

\title{
Promovendo a saúde da criança hospitalizada e do seu familiar por meio da música
}

Promoting hospitalized children's health, and their family member, through music

\author{
Jeane Barros de Souza \\ Universidade Federal da Fronteira Sul - UFFS, professora do curso de enfermagem \\ E-mail: jeanebarros18@gmail.com \\ Juliana Praxedes Campagnoni \\ Universidade Federal de Santa Catarina - UFSC, mestranda em Saúde Coletiva \\ E-mail: ju_campagnoni@hotmail.com \\ Emanuelly Luize Martins \\ Universidade Federal de Santa Catarina - UFSC, mestranda em Enfermagem \\ E-mail: emanuelly__martins@hotmail.com \\ Ricardo Demeneck Reinaldo \\ Universidade Federal da Fronteira Sul - UFFS, acadêmico do curso de enfermagem \\ E-mail: ricardodemeneck@gmail.com \\ Luana Reis \\ Universidade Federal da Fronteira Sul - UFFS, acadêmica do curso de enfermagem \\ E-mail: reiso5luana@hotmail.com \\ Tatiana Xirello \\ Enfermeira \\ E-mail: taty-xirello@hotmail.com
}

\section{RESUMO}

O presente trabalho tem o objetivo de compartilhar a experiência da utilização da música para a promoção da saúde de crianças hospitalizadas e de seus familiares. Trata-se de um relato de experiência acerca das atividades promovidas por um programa de extensão da Universidade Federal da Fronteira SUL - UFFS, com ações musicais semanais em um hospital público. O projeto contou com a participação de seis acadêmicos e dois docentes do curso de Enfermagem. A realização das intervenções musicais no hospital evidenciou que a música desperta nas crianças e em seus familiares sorrisos, abraços e emoções. As intervenções possibilitam, por alguns instantes, o esquecimento a respeito da dor, do medo, da espera e da incerteza em relação ao futuro, promovendo a saúde da criança hospitalizada e de seu familiar, sendo um caminho para a Enfermagem e demais profissionais da área da saúde seguirem em direção a um cuidado mais humanizado e holistico.

Palavras-chave: Promoção da Saúde, Saúde da criança, Hospitalização, Música, Enfermagem.

\section{ABSTRACT}

This paper aims to share the experience of using music to promote the health of hospitalized children and their families. This is an experience report about the activities promoted by an extension program at the Federal University of the Southern Border - UFFS, with weekly musical actions in a public hospital. The project counted on the participation of six academics and two professors of the Nursing course. The performance of musical interventions at the hospital showed that music awakens in children and their families smiles, hugs and emotions. Interventions allow, for a few moments, forgetting about pain, fear, waiting and uncertainty in relation to the future, promoting the health of hospitalized children and their families, being a path for Nursing and other professionals in the area health to move towards more humanized and holistic care.

Keywords: Health Promotion, Child Health, Hospitalization, Music, Nursing. 


\section{INTRODUÇÃO}

O processo de hospitalização engloba as mais diversas causas de doenças, sendo caracterizado como um periodo que provoca grande estresse ao doente e aos seus familiares, seja pela ausência do ambiente domiciliar ou pelo fato de terem que se adequar à rotina estabelecida na unidade cuidadora. No hospital, os indivíduos ficam à mercê dos cuidados prestados pela equipe multiprofissional de saúde, tornando-se de grande importância o estabelecimento de uma relação de confiança entre o indivíduo hospitalizado, seu familiar e o profissional (Xavier, Gomes \& Salvador, 2014).

Quando a hospitalização envolve o público infantil, a situação fica ainda mais complicada, já que a criança é retirada do seu espaço de brinquedos e estudo para outro local, que geralmente é mais quieto e sem diversão, podendo transmitir emoções de raiva ou desgosto, além de poder provocar na criança alguns distúrbios de ansiedade (Gomes \& Nobrega, 2015). Algumas crianças estabelecem internamente estratégias, como pensamentos positivos, aceitação da situação e até mesmo distração, com o objetivo de ocultar os estresses que surgem durante o período de diagnóstico e tratamento. Dessa maneira, durante o processo de hospitalização, percebe-se a relevância de incluir intervenções além da assistência já prestada, que irão acarretar benefícios para o físico, o psicológico e o social da criança (Xavier, Gomes \& Salvador, 2014; Motta et al., 2015).

Nesse sentido, é premente a necessidade de um olhar holístico da equipe de enfermagem para a criança e o familiar que a acompanha durante a hospitalização, com vistas a proporcionar um cuidado humanizado por meio da escuta e da empatia, a fim de potencializar as condições para que estes possam responder de forma positiva às adversidades que surgem no processo de doença e tratamento (Paiano \& Fernandes, 2015; Nogueira, 2015).

As atividades lúdicas podem contribuir para o processo terapêutico da criança hospitalizada, proporcionando momentos de lazer por meio da leitura, de jogos, de uma conversa atenta, da realização de pinturas e do contato com a música (Oliveira, 2016). A utilização da música como terapia para as diversas patologias está presente na enfermagem há muito tempo, auxiliando em processos marcantes, como na Segunda Guerra Mundial e nos cuidados prestados por Florence Nightingale1. A melodia das canções age promovendo a saúde, principalmente nas crianças, tornando perceptivel a influência que a música repercute no seu estado emocional. Além disso, o funcionamento cerebral também está ligado a essas sensações, como a memória e o aprendizado, o que interfere no bem-estar fisiológico (Areias, 2016).

A música transmite sensações até mesmo antes de uma criança nascer. Alguns efeitos são percebidos durante a fase infantil. Estes agem no sistema

\footnotetext{
${ }^{1}$ Enfermeira britânica, pioneira no cuidado e tratamento de feridos durante a Guerra da Crimeia. Foi reconhecida como "A dama da lâmpada". Fundadora da Enfermagem Moderna, voltada para a caridade, amor ao próximo, humildade e doação, que valorizou as condições ambientalistas, com desenvolvimento de ações para além do cuidado curativo (Dias \& Dias, 2019).
} 
nervoso que capta os estímulos externos ao corpo para melhor desenvolver o sistema motor e psicológico (Weigsding \& Barbosa, 2014). As melodias interferem diretamente no corpo, promovendo a melhora no aspecto fisiológico, no metabolismo e nas alterações dos sinais vitais, na dor, bem como reduz o estresse, a ansiedade e outros desconfortos (Paiano \& Fernandes, 2015).

Nessa perspectiva, foi criado pelo curso de Graduação em Enfermagem da Universidade Federal da Fronteira Sul - UFFS, o programa de extensão intitulado "Musicagem: a enfermagem promovendo a saúde no ambiente hospitalar por meio da intervenção musical". O programa de extensão surgiu com a finalidade de promover a saúde de crianças hospitalizadas e de seus familiares, bem como a de proporcionar momentos lúdicos de lazer e de esperança, preenchendo - com momentos de diversão, reflexão e alegria, tendo a música como ferramenta de atuação - o tempo ocioso e triste de um hospital infantil.

Diante dos resultados exitosos, surgiu este artigo. O relato tem como objetivo compartilhar a experiência da utilização da música para promover a saúde de crianças hospitalizadas e de seus familiares.

\section{MÉTODO}

As ações do programa de extensão iniciaram-se em 2018, com intervenções musicais realizadas semanalmente no espaço hospitalar, ao entardecer das terças-feiras. Desde então, a intervenção musical foi desenvolvida nos setores de recepção, de pronto atendimento (PA), de oncologia e de clínica geral do Hospital da Criança Augusta Müller Bohner, maior hospital infantil do oeste de Santa Catarina.

A equipe do programa de extensão é composta por seis acadêmicos e dois docentes do curso de graduação em Enfermagem. Cabe destacar que, para a seleção dos acadêmicos, levou-se em conta o interesse na realização de um trabalho voluntário, bem como a aptidão musical de cada um.

Os ensaios periódicos da equipe foram previamente organizados, visando à avaliação das atividades a serem desenvolvidas e a manutenção do repertório. Este é cuidadosamente escolhido, sendo composto por músicas que abordam temas como: superação, esperança, paciência, autoestima, amor e laços afetivos. Na atuação, a equipe foi organizada da seguinte forma: cinco cantores, um violino e dois violões.

No PA e na recepção do hospital foram realizadas intervenções musicais para as crianças e os familiares que ali aguardam atendimento. Em cada unidade de internação, foi solicitado à equipe de Enfermagem o prontuário de cada paciente, para que sejam previamente discutidos os casos clínicos. Escolhemse as músicas, observando-se melodias e letras, de acordo com a idade das crianças. Na unidade, um acadêmico da equipe visita todos os quartos a fim de verificar quais crianças e familiares desejam a intervenção musical, bem como para inspecionar rapidamente o estado psicológico deles para escolher a músi- 
ca conforme as necessidades de cada um. Além disso, são feitas apresentações para a equipe multiprofissional, com o intuito de aliviar o estresse provocado pelo trabalho e proporcionar um momento de lazer por meio da música. Nos quartos em isolamento, a equipe não adentra e busca cantar apenas na porta para que as crianças e familiares possam ao menos ouvir as canções.

As ações do programa de extensão são anotadas em ata para registrar os pacientes atendidos, os quartos em que a equipe realizou as intervenções musicais, as músicas entoadas, bem como as reações das crianças e dos seus familiares. O registro é feito com o intuito de assegurar as atividades desenvolvidas, caso haja intercorrências posteriores, além de os registros serem úteis para futuras pesquisas.

A avaliação das atividades musicais é realizada por meio do diálogo entre os integrantes do programa com as crianças, seus familiares e com a equipe multiprofissional que, constantemente, afirmam haver beneficios, como a promoção da alegria e da diversão para o hospital pediátrico, que geralmente é um lugar mais silencioso e entristecido.

\section{RESULTADOS E DISCUSSÃO}

Em se tratando de crianças, o periodo de hospitalização se caracteriza como um evento estressor para o paciente e seus familiares. Este ocasiona danos no crescimento e no desenvolvimento saudável da criança, pois as rotinas, as atividades e os fluxos são diferentes dos que ela está habituada em sua casa, além da exposição a todas as técnicas e procedimentos realizados para promover a recuperação, que geralmente causam medo e desespero (Coyne, 2017; Neutzling et al., 2017).

Durante o periodo de hospitalização é relevante desenvolver estratégias que contribuam para a regulação comportamental das crianças, de maneira que os fatores de estresse sejam controlados, assim como sua adaptação frente à hospitalização e às situações adversas que advêm desse período. Uma das estratégias que colaboram para essa regulação é a utilização do lúdico (Gomes \& Nóbrega, 2015; Silva \& Piovesan, 2018; Pinto et al., 2015).

Entende-se que as atividades lúdicas contribuem para o desenvolvimento infantil, pois, mesmo em periodo de hospitalização, as crianças continuam a desenvolver seus aspectos físicos e mentais (Silva \& Piovesan, 2018). O lúdico é de fácil aplicação e, além de contribuir para um cuidado humanizado, esse abarca diversas formas, variando desde o estabelecimento de um diálogo até o uso da música (Pinto et al., 2015).

A música é uma estratégia de promoção da saúde que oportuniza momentos de conforto e reduz a tensão, os sentimentos de dor e a ansiedade que estão presentes em uma hospitalização (Santana, Zanini \& Sousa, 2014). Também possibilita para aqueles que a ouvem momentos de lazer, descontra- 
ção, socialização e alegria, contribuindo para que as crianças e seus familiares expressem seus sentimentos e emoções contidos (Weigsding \& Barbosa, 2014).

Como forma terapêutica, o contato com a música promove uma melhoria de ordem física, psicológica, cognitiva e espiritual, pois cria estímulos cerebrais que provocam o aumento da serotonina - neurotransmissor envolvido na comunicação entre neurônios -, possibilitando que haja diminuição do estresse, da dor, da depressão e da ansiedade nos indivíduos hospitalizados (Perkins et al., 2018).

O efeito da música consiste em estimular as células cerebrais, aumentando o nível de serotonina e, dessa forma, melhorando o humor e/ou a disposição. Apesar de serem pessoas diferentes, fica evidente que a música transmite paz e esperança para as crianças e seus familiares, estimulando a liberação de endorfinas neuro-hormonais produzidas na hipófise. Ela proporciona uma potente ação analgésica, o que estimula a sensação de bem-estar, conforto e melhoria de humor (Areias, 2016).

A utilização da música em hospitais visa integrar um cuidado eficiente e mais humano, em consonância com o conceito ampliado de saúde, que ao considerar o ser humano como um todo em suas multiplicidades, para além do corpo físico, contribui para que sua hospitalização e recuperação sejam de qualidade, reduzindo, assim, os riscos de agravos nas condições de saúde dos pacientes (Cunha \& Oliveira, 2016).

A música também tem o efeito de provocar excitação ou calmaria conforme o ritmo e o ambiente criados (Areias, 2016). Nessa perspectiva, para a realização da intervenção musical, a equipe de atuação do programa de extensão desenvolveu um repertório com músicas diferenciadas para atender à criança e seu familiar de acordo com o momento que estão vivenciando, pois eles poderão necessitar, em certas ocasiões, de músicas mais calmas e, em outras, de músicas agitadas, a fim de trazer reflexão e ou diversão, respectivamente.

Ao visitar a unidade oncológica do hospital, a equipe necessita escolher músicas assertivas que tragam mensagens de esperança e renovação, pois há crianças que já estão internadas há várias semanas, enfrentando problemas ao longo do processo da doença. Destacando-se que a hospitalização modifica completamente a dinâmica familiar, interferindo nas relações e nas interações entre os próprios familiares, já que a criança necessita passar por frequentes internações terapêuticas agressivas, além da vulnerabilidade social que a doença ocasiona devido à precariedade das condições econômicas, sociais e culturais de algumas familias (Negreiros et al., 2017).

A música para os familiares das crianças hospitalizadas também é importante e significativa. Ela faz fluir lembranças de vivências, pois muitas canções estão ligadas a memórias alegres ou tristes, ajudando em uma melhor interação em situações de insônia e depressão (Motta et al., 2015). Como uma forma de expressar emoções e sentimentos, a equipe percebe, ao cantar para as crian- 
ças e seus familiares, o despertar de sorrisos, abraços, choros e até mesmo o desejo de interação com o grupo, manifestado no bater palmas.

Vale destacar novamente que, antes de entrar nos quartos, um integrante da equipe verifica se as crianças e seus familiares desejam a intervenção musical. Geralmente, esses aceitam e aguardam com ansiedade a chegada da equipe em seus quartos, tirando fotos e filmando a equipe cantando.

Esse é um importante momento para a criança hospitalizada, pois, ao se pedir permissão para entrar em seu quarto, evidencia-se a preocupação com sua opinião, demonstrando que ela tem o poder e a autonomia de decidir o que virá a seguir, sem que um familiar ou profissional de saúde tome a decisão por ela, o que amplia seus horizontes e contribui para a promoção de mudança e colaboração na sua hospitalização (Carvalho \& Cruz, 2015).

Muitas crianças, logo após a equipe adentrar cantando em seu quarto, já demonstram mudança na fisionomia. As crianças ficam admiradas com os instrumentos, pois se torna uma atividade diferente, tirando-as da sua rotina hospitalar e chamando sua atenção para algo novo e divertido.

Os olhares das crianças que recebem pela primeira vez a intervenção musical são de muita admiração, surpresa, encantamento e também de espanto, que, com o desenrolar da música, se dissolve em sorrisos ou em brilho no olhar ao se entregarem ao ritmo das canções. Estas despertam o desprendimento da situação em que se encontram, fazendo-as esquecerem-se, por alguns instantes, a dor, o medo, a espera e a incerteza com relação ao futuro.

No entanto, no decorrer das ações no espaço hospitalar, a equipe foi percebendo a necessidade de realizar adaptações, como soprar bolinhas de sabão e manusear fantoches para chamar atenção das crianças durante a apresentação das músicas. Além disso, foram utilizados lenços coloridos nas mãos dos cantores, com o objetivo de manter a atenção principalmente dos pequeninos. Foi pensada também a inclusão de um instrumento de percussão a fim de proporcionar maior ritmo e animação aos momentos de intervenção musical. Tais adaptações se configuram como uma tática favorável para que as crianças pudessem prestar maior atenção e interagir com a equipe do programa de extensão.

Outra questão a salientar é que por meio da intervenção musical se estabelece um vínculo imediato entre a equipe e as crianças e seus familiares, utilizando-se de atributos próprios da relação humana, fundamentais na construção de vínculo no espaço do cuidado (Silva, Terra, Gonçalves \& Souto, 2014). Esse laço instantâneo é perceptivel no olhar emocionado das crianças e dos familiares, momento esse que dura segundos, mas toca profundamente, ficando evidente que a música tem a capacidade de estabelecer laços que as palavras não poderiam. Por vezes, o riso dá lugar ao choro, abrindo espaço para as emoções fluirem, principalmente na oncologia, em que a equipe do programa de extensão se solidariza com o sofrimento e com a luta pela vida, despertando um sentimento tão nobre e significativo que é a empatia. 
As demonstrações de carinho e gratidão das crianças e de seus familiares são frequentes. Essas evidenciam o quão importante foi terem recebido a intervenção musical em seus quartos. Algumas crianças apreciam tanto a intervenção que, por vezes, saem bem animadas dos seus quartos e passam a acompanhar a equipe nos corredores para poderem escutar todo o repertório musical.

É importante destacar que a equipe de atuação também se organiza de uma maneira a evitar a infecção cruzada. Primeiramente, é realizada a intervenção na unidade oncológica e, em seguida, realiza-se a higienização das mãos e a fricção com álcool gel, para somente depois seguir para as outras unidades de internação. Tendo-se em vista que a equipe de saúde é o principal vínculo de infecção cruzada desses ambientes (Badran, 2007), os integrantes da equipe não tocam nas crianças e nem em seus familiares enquanto cantam, com o objetivo de evitar infecções. Em alguns momentos, quando se faz necessário, devido ao choro emotivo ou a pedidos de abraços, os membros da equipe os tocam e os acalentam, tomando o cuidado de logo em seguida realizar a higiene das mãos para dar continuidade à ação nos demais quartos.

No ambiente de isolamento, as atividades e brincadeiras realizadas por grupos de apoio ficam restritas, desencadeando, consequentemente, um processo de isolamento social para a criança e seus familiares (Rocha, 2016). As crianças que estão em isolamento não se tornam critério de exclusão para a equipe; apenas há uma maior cautela com a intervenção prestada. Ou seja, canta-se apenas da porta e/ou da janela de vidro, sem adentrar nos quartos, para que, de alguma forma, as crianças e seus familiares possam também receber a intervenção musical.

Os profissionais da saúde enfrentam muitos desafios para prestar o cuidado a uma criança hospitalizada devido à necessidade de terem que realizar técnicas e procedimentos dolorosos e que podem despertar o medo. Mas, além disso, há o envolvimento da carga emocional por parte dos profissionais, que, em muitas situações, sofrem e possuem sentimento de impotência diante de certos casos, presenciando e sentindo momentos de sofrimento, de dor e de perda (Zanatta \& Lucca, 2015).

Com o programa de extensão, tem-se a oportunidade de também compartilhar a música com os diversos profissionais que atuam no hospital, desde a equipe multiprofissional da saúde até com os recepcionistas, com a equipe da copa e também com a da limpeza, tendo a finalidade de aliviar o estresse laboral e proporcionar alguns minutos de distração, relaxamento e bem-estar no ambiente de trabalho.

Para realizar as intervenções musicais todas as terças-feiras, os acadêmicos e docentes saem do conforto do lar, dispostos a cantar e assim despertar pelo menos um sorriso das crianças hospitalizadas, de seus familiares e dos profissionais. No entanto, ao realizar a ação no hospital, também fazem o bem para si, pois, enquanto cantam, os membros da equipe se desligam do mundo e dos seus diversos afazeres - das provas para estudar ou corrigir, dos seus 
problemas -, proporcionando saúde para todos os envolvidos no processo. Além disso, a participação no programa de extensão tem possibilitado aos acadêmicos de Enfermagem, tanto para os que estão iniciando a formação quanto para os que já estão nas fases finais, a oportunidade de desenvolver um olhar diferenciado sobre a criança e sobre o seu cuidado, exercitando o processo de humanização, do cuidado holístico e o despertar da empatia.

As visitas semanais no ambiente hospitalar trazem a percepção de que algumas crianças já não estão mais hospitalizadas, podendo ter recebido alta ou ido a óbito. Por isso, é necessário que todos os envolvidos saibam a importância de cuidar de si e que conheçam seus limites para que o cuidado seja feito e o retorno para casa seja rodeado de paz e sentimento de dever cumprido (Silva, Terra, Gonçalves \& Souto, 2014). O fato é que, a cada nova intervenção musical, surge a oportunidade de promover a saúde no hospital, o que mobiliza os acadêmicos e docentes envolvidos a continuarem participando do programa de extensão de forma voluntária.

\section{CONSIDERAÇÕES FINAIS}

A intervenção musical traz muitos benefícios físicos e psicológicos para os indivíduos, independente da faixa etária, sendo um recurso eficaz para o cuidado da criança hospitalizada, do seu familiar e dos profissionais que atuam no espaço hospitalar.

A música é uma intervenção de baixo custo para o hospital e para quem dela participa. É uma forma de tratamento não farmacológico, não invasivo e pode ser empregado em qualquer espaço, inclusive dentro do próprio quarto de um individuo hospitalizado, visando promover o processo de desenvolvimento das crianças, da família e dos profissionais, uma vez que todos ficam envolvidos quando escutam uma música, podendo transformar um momento triste em alegria.

A participação no programa de extensão permitiu a comunicação entre o ensino, a pesquisa e a extensão, levando os acadêmicos de Enfermagem à compreensão de que a prática gera um compromisso com ações conforme a necessidade da população assistida, permitindo a construção de seres mais conscientes, participativos e criativos no meio social, em prol da qualidade da assistência em saúde ofertada. Além disso, no caminhar do programa de extensão, a equipe tem buscado aproveitar os talentos de todos os envolvidos, seja cantando ou tocando instrumentos, seja numa conversa ou num abraço acolhedor, usando a criatividade e fortalecendo os laços entre si para o desenvolvimento das ações, fato esse que também agregou intensamente à vivência dos acadêmicos, tanto no crescimento pessoal como profissional.

A equipe do programa de extensão tem promovido a saúde da criança hospitalizada, sugerindo um caminho para a Enfermagem e demais profissionais da área da saúde seguirem em direção a uma infância mais saudável. No 
entanto, existem limitações na utilização da música na área da saúde, uma vez que nem todos os profissionais possuem algum conhecimento musical. Além disso, a dificuldade no desenvolvimento dessa prática pode representar outra no de pesquisas que tragam evidências cientíicas sobre a utilização da música como promotora da saúde no espaço hospitalar. Por outro lado, nota-se também que os currículos da área da saúde pouco têm valorizado aspectos que ampliem o processo de diagnóstico-terapêutico para além da área biológica.

Nessa perspectiva, torna-se importante que a equipe de saúde se mobilize, de forma intersetorial, com o intuito de realizar pesquisa e compartilhar as experiências envolvendo a intervenção musical e outras tecnologias que utilizem maneiras criativas e econômicas de realizar o cuidado e promover a saúde das crianças hospitalizadas e de seus familiares. Salienta-se que a equipe de atuação desse programa de extensão já está organizando uma pesquisa sobre os benefícios da intervenção musical, a fim de obter evidências cientíicas acerca da utilização da música como promotora da saúde no espaço hospitalar, ficando a sugestão para que outros hospitais do pais e do mundo abracem essa ideia. 


\section{REFERÊNCIAS}

Areias, J. C. (2016). A música, a saúde e o bem-estar. Nascer e Crescer; 25(1), 7-10. http://www.scielo.mec.pt/scielo.php?script=sci_arttext\&pi$\mathrm{d}=\mathrm{S} 0872-07542016000100001 \& \operatorname{lng}=$ pt\&nrm=iso.

Badran, A. V. (2007). Estudo da contaminação microbiana em aventais privativos e não privativos na UTI - Pediátrica do Hospital Central da Santa Casa de São Paulo. Arquivos Médicos dos Hospitais e da Faculdade de Ciências Médicas da Santa Casa de São Paulo; 53(3), 77-80. file://C:/Users/Especial/Downloads/444-858-1-SM.pdf.

Carvalho, M. J. L, \& Cruz, H. (2015). Promoção de autonomia em crianças e jovens em acolhimento em instituição. https://run.unl.pt/bitstream/10362/36520/1/ Brochura_Autonomia_Final_28_05.1.pdf.

Coyne, I. (2007). Children's experiences of hospitalization. Journal of Children Health Care; 10(4), 326-336. file:///C:/Users/Especial/Downloads/JCHC2OChildren39s2oexperiences2oof2ohospitalisation.pdf.

Cunha, L. G. H., \& Oliveira, M. C. (2016). Política de saúde para adolescentes na perspectiva dos direitos humanos: reflexões a partir de um hospital de trauma. XII Congresso nacional demandas sociais e politicas públicas na sociedade contemporânea; 1-27. file:///C:/Users/Especial/Downloads/14759-11748-1-PB.pdf.

Dias, L. P., \& Dias, M. P. (2019). Florence Nightingale e a História da Enfermagem. História da Enfermagem Revista Eletrônica - HERE; 10(2), 47-63. http://here. abennacional.org.br/here/v10/n2/a4.pdf

Gomes, G. L. L. \& Nóbrega, M. M. L. (2015). Anxiety in children following hospitalization: a proposal for a nursing diagnosis. RLAE; 23(5), 963-970. http://www. scielo.br/pdf/rlae/v23n5/0104-1169-rlae-23-05-00963.pdf.

Motta, A. B., Perosa, G. B., Barros, L., Silveira, K. A., Lima, A. S. S., Carnier, L. E., Hostert, P. C. C. P. \& Caprini, F. R. (2015). Comportamentos de coping no contexto da hospitalização infantil. Estudos de Psicologia; 32(2), 331-341. https://repositorio.unesp.br/bitstream/handle/11449/127302/S0103-166X2015000200331. pdf? sequence=1\&isAllowed=y.

Negreiros, R. V., Furtado, I. S., Vasconcelos, C. R. P., Souza, L. S. B., Vilar, M. M. G., Alves, R. F. (2017). A importância do apoio familiar para efetividade no tratamento do câncer infantil: uma vivência hospitalar. Revista Saúde e Ciência Online; 6(1), 57-64. http://www.ufcg.edu.br/revistasaudeeciencia/index.php/RSC-UFCG/ article/view/464/290.

Neutzling, B. R. S., Barlem, J. G. T., Barlem, E. L. D., Hirsch, C. D., Pereira, L. A., \& Schallenberguer C. D. (2017). Em defesa dos direitos da criança no ambiente 
hospitalar: o exercício da advocacia em saúde pelos enfermeiros. EEAN; 21(1), 1-9. http://www.redalyc.org/pdf/1277/127749356025.pdf.

Nogueira, I. L. S. (2015). A importância do ambiente físico hospitalar no tratamento terapêutico do paciente hospitalizado. IPOG - Rev Especialize On-line; 1(10), 1-15. http://businesstur.com.br/uploads/arquivos/e8ca8e183209c7041ef5bb8ofac481cf.pdf.

Oliveira, W. F. (2016). O núcleo de humanização, arte e saúde: uma experiência coletiva de produção social de saúde. CBSM; 8(18), 198-211. http://incubadora. periodicos.ufsc.br/index.php/cbsm/article/viewFile/4224/4632.

Paiano, L. A. G. \& Fernandes, L. M. (2015). Uso de intervenção musical em pacientes internados em unidade de terapia intensiva: estudo piloto. REUFSM; 4(4), 813-824. https://periodicos.ufsm.br/reufsm/article/view/13015.

Perkins, R. S., Boyce, M., Byrtek, M. C., Ellis, R. C., Hill. C., \& Fitzpatrick, P. S. (2018). Demirel S. Roadmap to wellness: Exploring live customized Music at the bedside for hospitalized children. Frontiers in Oncology; 8, 1-6. https://www.frontiersin. org/articles/10.3389/fonc.2018.00021/full

Pinto, M. B., Andrade, L. D. F., Medeiros, A. P. G., Santos, G. L. O., Queiroz, R., \& Jales, R. D. (2015). Atividade lúdica e sua importância na hospitalização infantil: uma revisão integrativa. Revista Universidade Vale do Rio Verde; 13(2), 298-312. http://periodicos.unincor.br/index.php/revistaunincor/article/view/2292/ pdf_378.

Rocha, E. P. (2016). Produção e validação de tecnologia educacional para familiares de crianças com leucemia linfocitica aguda em isolamento protetor [Dissertação, Universidade Federal do Amazonas, Manaus]. http://200.129.163.131:8080/bitstream/tede/5683/5/Disserta\%C3\%A7\%C3\%A30\%20-\%20Ellen\%20Pessoa\%20 Rocha.pdf.

Santana, D. S. T., Zanini, C. R. O., Sousa, A. L. L. (2014). Efeitos da música e da musicoterapia na pressão arterial: uma revisão de literatura. Revista InCantare; 5(5), 37-57. http://periodicos.unespar.edu.br/index.php/incantare/article/view/261.

Silva, A. A., Terra, M. G., Gonçalves, M. O., \& Souto, V. T. (2014). O Cuidado de si entre profissionais de Enfermagem: revisão das dissertações e teses brasileiras. RBCS; 18(4), 346-352. file:///C:/Users/Especial/Downloads/15263-55331-1-PB. pdf.

Silva, G. H., Piovesan, J. C. (2018). Música no ambiente hospitalar: uma possibilidade de proporcionar alegria e ludicidade na internação. Rev. Vivências; 14(26), 204-219. http://www.reitoria.uri.br/ vivencias/Numero_026/artigos/pdf/Artigo_17.pdf. 
Weigsding, J. A., \& Barbosa, C. P. (2014). A influência da música no comportamento humano. Arquivos do Mudi; 18(2), 47-62. http://www.periodicos.uem.br/ ojs/index.php/ArqMudi/article/viewFile/25137/pdf_5.

Xavier, D. M., Gomes, G. C, \& Salvador, M. S. (2014). O familiar cuidador durante a hospitalização da criança: convivendo com normas e rotinas. Esc Anna Nery, 18(1), 66-74. https://www.scielo.br/pdf/ean/v18n1/1414-8145-ean-18-01-0o68. pdf

Zanatta, A. B., \& Lucca S. R. (2015). Prevalência da sindrome de burnout em profissionais da saúde de um hospital oncohematológico infantil. Revista da Escola de Enfermagem - USP; 49(2), 253-260. http://www.redalyc.org/ $\mathrm{pdf} / 3610 / 361038470010 . \mathrm{pdf}$.

Data de submissâo: 01/04/2020

Data de aceite: 30/10/2020 